\title{
Thermal Comfort Evaluation of Offices Integrated Into an Industrial Building. Case Study of the Basque Country
}

\author{
Iñigo RODRIGUEZ VIDAL ${ }^{1}$, Xabat OREGI ${ }^{2 *}$, Jorge OTAEGI ${ }^{3}$ \\ ${ }^{1-3}$ CAVIAR Research Group, Department of Architecture, University of the Basque Country UPV/EHU, \\ Plaza Oñati, 2, 20018 Donostia - San Sebastián, Spain
}

\begin{abstract}
This paper reports the indoor air operative temperature and relative humidity outcomes of a sixteen-month monitoring campaign of an administrative area in an industrial building in Tolosa (Spain). In a survey, users reported indoor climate dissatisfaction during the working hours, such as severe discomfort in the conference rooms due to excessive cold or overheating, poor indoor air quality or inadequate response of the HVAC systems. Internal operative temperatures and relative humidity have been analysed with and without environmental conditioning systems to study passive performance and effectiveness of active systems. These two parameters have been analysed in hourly intervals, during summer and winter periods. On the basis of the obtained data, the degree of thermal comfort of the users was evaluated, which allowed a comparison between the users' self-reported perception obtained through surveys and the monitored data. Three different standards were used to assess thermal comfort, namely the European Standard UNE-EN ISO 7730, the Spanish Regulations for thermal installations in buildings (RITE) and the criteria established by the National Institute for Occupational Safety and Health (INSHT). The study has made it possible to detect the main aspects that have a direct influence on user discomfort.
\end{abstract}

Keywords - Monitoring campaign; operative temperature; post occupancy evaluation (POE); relative humidity; survey; thermal comfort

\section{INTRODUCTION}

There are numerous scientific studies that have evaluated and published different analyses linked to thermal comfort in different types of buildings such as offices [1]-[5], schools [6]-[8] or homes [9]-[11]. However, the typology that will be analysed throughout this document has rarely been analysed in previous studies. This study will focus on assessing the thermal comfort of the administrative spaces (offices and meeting rooms) that are located within industrial buildings, which occupy a small surface area and have little productive weight in relation to the building as a whole. As a result, aspects such as energy efficiency or thermal comfort of these rooms usually remain in the background to prioritize the productive optimization of the industrial process. However, in regions such as the Basque Country (north of Spain), the weight of the industrial sector reaches $24.2 \%$ of GDP, causing $33 \%$ of the population to work in industrial buildings [12]. Although currently there are no differentiated data of industry workers among those who carry out workshop and office tasks, it is clear that administrative activities with

* Corresponding author.

E-mail address: xabat.oregi@ehu.eus 
different range of activity are developed in all these buildings (from single-person to 50 workers as in the case analysed).

In this case, the study focuses on evaluating different aspects related to the thermal comfort of the administrative areas of PANELFISA, a company dedicated to the manufacture of screws and other fastening elements using cold stamping. As a starting point, the work focused on the perception of the users who usually work in these rooms, who describe a series of problems during the working day such as strong discomfort in the small first floor meeting rooms due to overheating from solar radiation; great discomfort in large first floor meeting rooms due to excessive cold; hot and cold environments at different times on the ground floor offices; poor air quality in general; the poor response of air-conditioning systems to these problems; or the high energy consumption of the HVAC system (which accounts for $66 \%$ of the total electricity consumption of the administrative area).

\section{AIMS AND METHODOLOGY}

Given this situation, this work focuses on obtaining a clear picture of the behaviour of the rooms evaluated in the face of the outside climate and the use to which it is intended. For this, the following tasks have been carried out: description of the building (1), worker surveys (2), PMV and PPD assessment (3), air temperature and relative humidity monitoring (4), thermal comfort analysis based on the monitored data (5).

\section{Current State of the Case Study}

\subsection{Description of the Building and the Administrative Area}

The building where the offices that are the object of this study are located in the Aldaba-Berazubi Industrial Area in Tolosa (Spain) and it was erected in 1993. The administrative area (offices and meeting rooms), with $630 \mathrm{~m}^{2}$, is integrated in the southwest facade (see Fig. 1) within the large industrial pavilion $\left(5725 \mathrm{~m}^{2}\right)$.
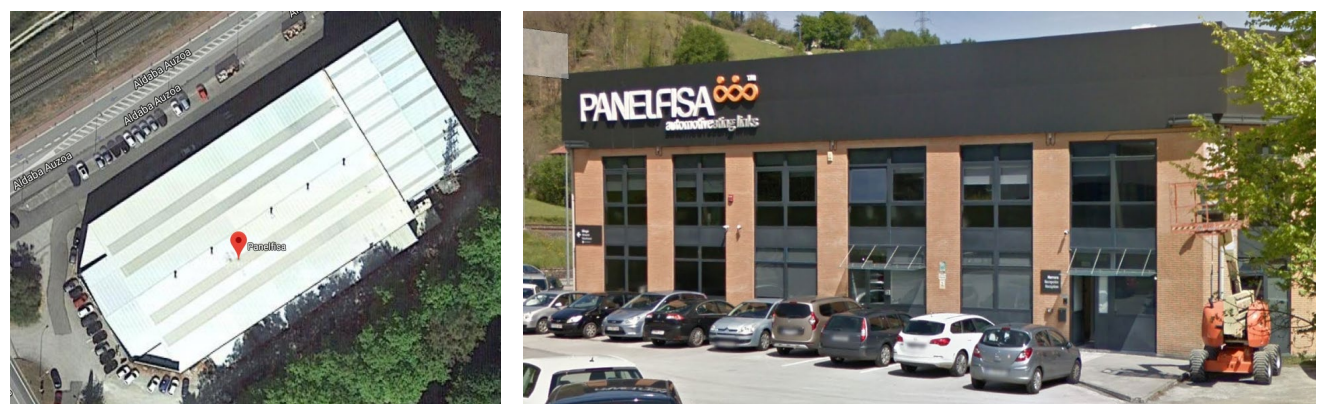

Fig. 1. Aerial view of the building, highlighting the administrative area (left) and view of the exterior facade of the administrative area (right). Source: Google Maps.

The building has the typical construction of an industrial pavilion, made up of a series of parallel frames with a structure of laminated steel profiles and enclosures in lacquered ribbed metal sheets [13]. On the west facade there is a body containing the offices, which consists of two floors.

The enclosure is made up of facing brick panels combined with vertical openings closed with panned windows. The envelope of these rooms is not thermally insulated. Windows have aluminium frames without thermal break $\left(\mathrm{U}\right.$-value $\left.=5.7 \mathrm{~W} /\left(\mathrm{m}^{2} \mathrm{~K}\right)\right)$ with double glazing with a $6 \mathrm{~mm}$ air gap $(4+6+4)$, 
with a $U$-value $=3.3 \mathrm{~W} /\left(\mathrm{m}^{2} \mathrm{~K}\right)$. It should be noted that these administrative areas or offices are part of a building whose main use is industrial. Therefore, due to this use, according to the regulations of the period when it was built, the envelope of the administrative area had no legal obligation to have to comply with the minimum thermal values determined for other building typologies. This lack of obligation influences directly in this kind of administrative areas, because most of them do not meet the minimum requirements specified by the national building regulations [14].

Solar protection is provided by interior blinds. This does not prevent the entry of heat when there is direct solar radiation. All rooms are connected to a mechanical ventilation system with heat recovery and air conditioning. The spaces that have a facade to the outside have additional natural ventilation through the windows, which are free to operate by the occupants. The air-conditioning installation is carried out by means of two VRF heat pumps of 40 and $25 \mathrm{KW}$.

The ground floor offices (see Fig. 2) are where most of the daily activity takes place. They are grouped in tables of 4 workers with a typical technical office activity (F0.1). The first floor is used as a meeting space (see Fig. 3). It has 3 small meeting rooms (F1.3, F1.4 and F1.5), a medium one (F1.2) and a large one (F1.1). It also has a kitchen-dining space, computer server room, changing rooms and bathrooms, which are outside the scope of this study.

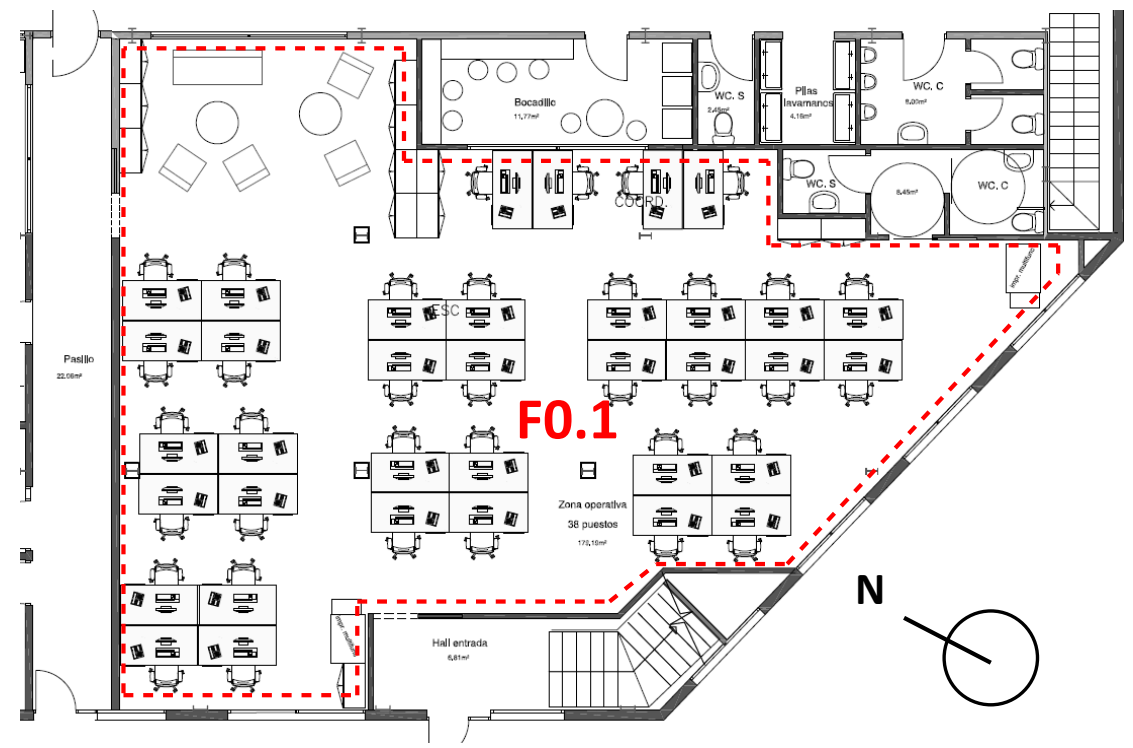

Fig. 2. Ground floor plan. The red line defines the scope of the room evaluated on the ground floor.

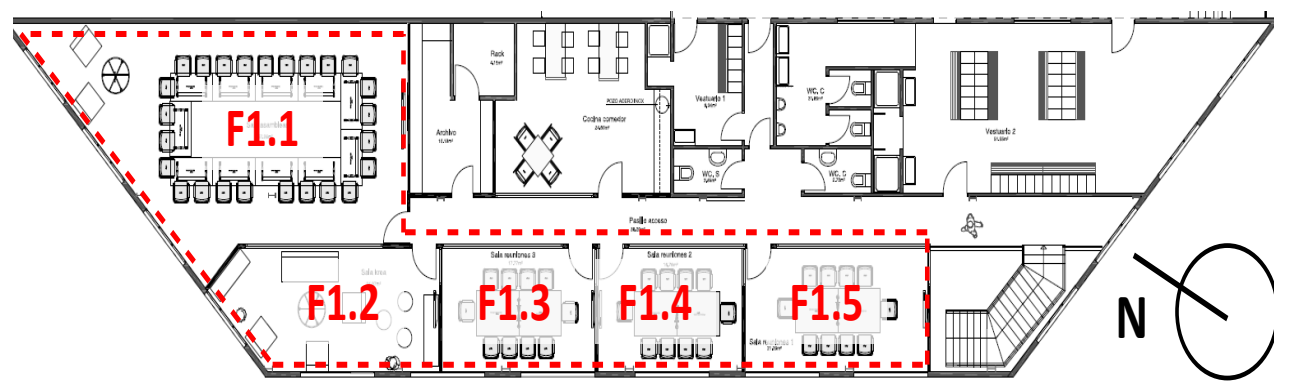

Fig. 3. First floor plan. The red line defines the scope of the room evaluated on the first floor. 


\subsection{Surveys}

The survey is divided into the general perception during the year, divided into the winter and summer periods and the perception of the day of the survey. The number of workers who have carried out the survey is 34 ( 17 women and 17 men), out of the approximately 50 who work at the same time. Regarding their daily activity (defined as in UNE-EN ISO 7730 [15]), $68 \%$ report that their activity is sedentary, $20 \%$ "rest or sitting" and $12 \%$ standing light or medium activity [16]. In relation to the clothing used during work (in winter and summer), the results show the use of relatively light and informal clothing typical of office work in general, with a CLO value of between $0.6-1$.

Regarding satisfaction with the levels of temperature, humidity and air quality, the survey allowed to obtain the following conclusions:

- Perceived Temperature in winter: $67 \%$ of users (12 men and 11 women) report that the temperature is slightly hot or thermally neutral, $18 \%$ slightly cold and the rest $15 \%$ cold or hot.

- Perceived Temperature in summer: $48 \%$ of users ( 9 men and 7 women) define that the temperature is hot or very hot, $33 \%$ slightly hot or neutral and the remaining $19 \%$ slightly cold.

- Perceived Relative Humidity in winter: $79 \%$ of users perceive a degree of neutral humidity in winter. A reduced number of users indicate a perception of moisture and slightly dry.

- Perceived Relative Humidity in summer: $85 \%$ of users perceive a degree of neutral humidity in summer.

Another section of the survey has focused on asking about local thermal discomfort. At this point, the authors tried to detect the inconvenience caused by cold walls or floors, hot facades, etc. The first point analyses the temperature perception of the environment with respect to the body:

- Floor: $88 \%$ of users do not perceive any temperature difference between the floor and the body.

- Façade walls: $53 \%$ of users do not perceive any temperature difference between the facade and the body. Although $47 \%$ mark somewhat hot and somewhat cold, it is probably due to the position that each worker occupies in the office space, near or far from the facade.

- Windows: only $41 \%$ of users do not perceive any temperature difference between the windows and the body, $36 \%$ mark somewhat hot or somewhat cold, $20 \%$ cold or hot and $3 \%$ very hot.

Within this thermal discomfort, another aspect analysed focuses on internal air currents (indoor air movement) and external (due to the opening of windows and doors). The conclusions show that more than $65 \%$ and $38 \%$ of users complain of medium or severe discomfort in relation to internal and external currents, respectively. Finally, the survey asked about the general perception of air quality, with most opinions rating indoor air as neither good nor bad (48\%), bad $(23 \%)$ or very bad ( $3 \%)$. In this case, only $21 \%$ have defined the quality of the indoor air as good or very good. This negative perception of air quality may be due to odours from the factory itself as well as a low capacity of the ventilation machine to renew the air.

In turn, a section of the survey focused on assessing office spaces from $0-9$ ( 0 reflects the minimum score and 9 the maximum score). The results show a general malaise of the spaces, reaching the approved (4.5 points) all spaces, but with a very fair value (5.6 is the maximum score). The ground floor spaces are best rated, with the first-floor meeting rooms being the worst rated (average score of 4.6).

Finally, the last section of the survey allowed each user to add a series of general comments about office comfort and in what aspects they would improve the system. The highlights among the users can be grouped into several recurring themes detected in this study: sometimes excessive 
heat and other cold; excess heat in small meeting rooms; poor response of the air conditioning; poor air quality; and need for ventilation or direct input from outside air.

\subsection{PMV and PPD Indexes}

In addition to direct reporting by the users, their answers on level of clothing and activity, combined with the data obtained through monitoring, were used to calculate PMV (Predicted Mean Vote) and PPD (Predicted Percentage Dissatisfied), following the method defined in the UNE-EN ISO 7730 Standard. This allows to separate the objective information obtained in the survey (MET, CLO) from subjective perception of the individuals. The calculation was made for the workers taking the survey on April $4^{\text {th }}, 2019$. Results show a clear bias towards the "cool" and "slightly cool" section (see Fig. 4). Mean PMV is -0.90 for women and -0.50 for men (average: 0.70$)$, which is outside the comfort range $(-0.50$ to +0.50$)$. The resulting PPD is $16.82 \%$ on average ( $21.71 \%$ for women, $11.94 \%$ for men), which indicates an uncomfortable/very unsatisfactory global thermal comfort.

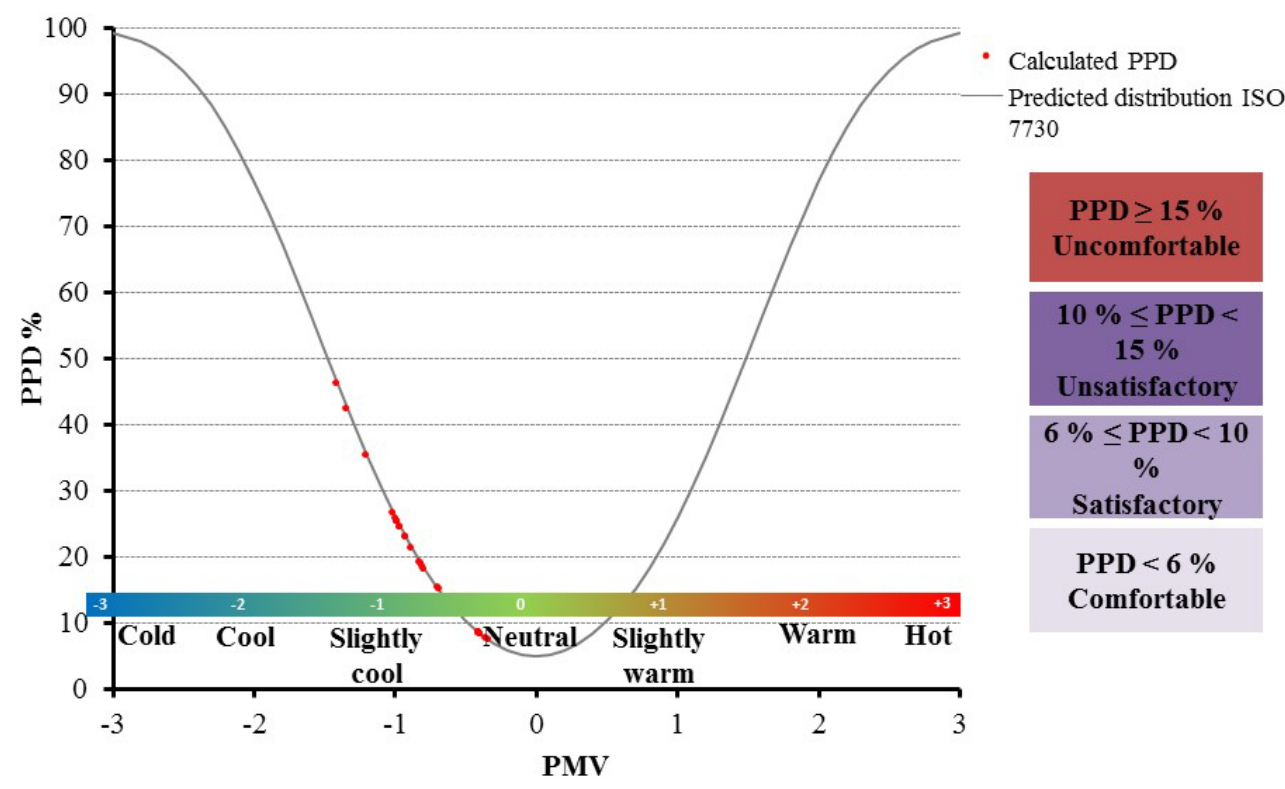

Fig. 4. Calculated PMV and PPD values during the day of the user survey (2019-04-04).

\subsection{Air Temperature and Relative Humidity Monitoring}

The spaces described above have been monitored by means of a remote system with access from My Open Hab [17]. This study analyses the two monitored parameters separately: internal temperature and relative humidity (see Fig. 5).

\subsubsection{Internal Temperature}

First, the results will be analysed at times when there is no active heating or cooling, on holidays, for example. The analysis is performed on a hot summer day and a cold winter day to assess its behaviour in conditions of extreme outdoor temperature. This allows us to assess the capacity of 
the building envelope to maintain cold or heat, that is, its insulation capacity, and its ability to control solar radiation, known as "passive behaviour". Subsequently, the same analysis is done on days with occupation and active systems turned on. Days with low occupancy and high occupancy are chosen. This also allows us to find out the responsiveness of active systems (air conditioning).

Internal temperature without active environmental conditioning systems: The hot day selected was August 4, 2018 (Saturday), a very hot day (with a peak temperature of almost $43{ }^{\circ} \mathrm{C}$ ) and with high solar radiation. The studies show that the ground floor office (F0.1), with fewer openings, maintains a stable temperature. The maximum temperature reached is $30^{\circ} \mathrm{C}$ at $18: 30 \mathrm{~h}$, a little later than the outside temperature peak. The minimum temperatures in the offices located on the first floor are between $26-27^{\circ} \mathrm{C}$. However, they reach maximum values of almost $44{ }^{\circ} \mathrm{C}$. This data allows us to infer that the spaces analysed, as they are not equipped with effective solar protection, suffer from strong variations in temperature associated with solar radiation (especially the spaces on the first floor). As to the coldest day, January 6, 2019 (Sunday) was selected, a day when the outside temperature fell from $0{ }^{\circ} \mathrm{C}$. The ground floor office is kept in a range between $17-19^{\circ} \mathrm{C}$. In relation to the spaces on the first floor, it can be seen that the large meeting room (F1.1) reaches a minimum of $6^{\circ} \mathrm{C}$ during the night. This indicates its low thermal insulation and the higher impact of the north facade. Likewise, it is to be assumed that there is a notable impact due to being directly above an un-conditioned space. The rest of the rooms show a similar pattern. The minimum temperatures are higher in rooms that are in contact with the conditioned spaces (F1.3, F1.4 and F1.5) and lower in offices that are above unconditioned spaces (F1.1 and F1.2).

Internal temperature with active environmental conditioning systems: In this type of evaluation one of the key parameters is usually the level of occupancy of the spaces. Although the original study evaluated three scenarios (low, medium and high occupancy), in order to reflect a more common scenario, this section will focus on analysing the internal temperatures with an average (medium) user occupation. For the summer period, 11 September 2018 has been selected, a normal working day when all the spaces are occupied and there is still a high late summer outdoor temperature (up to $42{ }^{\circ} \mathrm{C}$ ) the office on the ground floor has remained overnight at about $22{ }^{\circ} \mathrm{C}$, a comfortable temperature in principle. In the first period from 6:00 to 9:00 a.m. there is a rise in temperature, probably due to the occupation and the office equipment. After 9 a.m. there is a drop in temperature, probably because the cooling system is activated. It then rises again to $26^{\circ} \mathrm{C}$. This cycle is repeated in the afternoon until $6: 30 \mathrm{p} . \mathrm{m}$. when the system is deactivated. Uncontrolled operation of the system is clearly shown, switching from cold to hot, but not being able to maintain comfort in a stable manner. The offices located on the first floor show an even more unstable pattern. The meetings cause a sudden increase in temperature to which is added that caused by solar radiation. At 5:00 p.m., a series of meetings cause the cooling system to turn on, lowering the temperature in all of them uniformly to the minimum of $6: 30 \mathrm{p} . \mathrm{m}$. For the winter period, January 8 has been selected, a normal working day in which all the spaces are occupied and the outside temperature drops to $5^{\circ} \mathrm{C}$ during the night and has a peak of $9{ }^{\circ} \mathrm{C}$ at $14: 00 \mathrm{~h}$. The ground floor office activates the heating system at 6:00 h. However, it has trouble going from the initial $13{ }^{\circ} \mathrm{C}$ to $21-22^{\circ} \mathrm{C}$, a value that is reached at 15:00 h. At 16:00 the system is stopped and the temperature drops again to $16^{\circ} \mathrm{C}$. The offices on the first floor undergo the same process as on other days. The meetings cause the heating system to be activated, as they are very cold and the meeting itself cause the temperature to shoot up to $29^{\circ} \mathrm{C}$ in some cases. This causes windows to open and the temperature to drop. This cycle is repeated numerous times. Some rooms set the thermostat again to a temperature that is maintained throughout the evening. In general, it shows us a building with a serious lack of insulation of the envelope, little inertia, and no solar protection. This, together with the activity carried out, the use of offices, in which the high and variable internal sun loads; make the behaviour of the building depend entirely on the mechanical installations. 


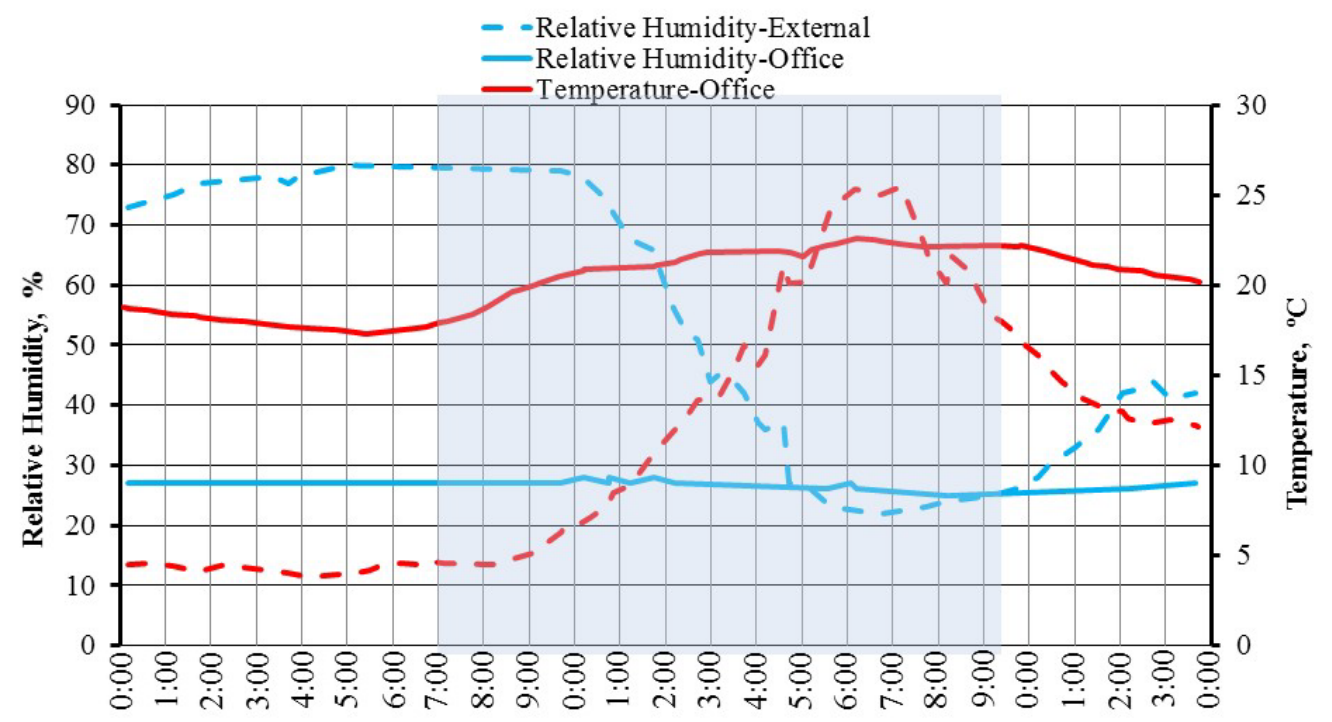

Fig. 5. Example of monitored data (relative humidity and temperature) in the ground floor office (F0.1) during the day of the user survey (2019-04-04).

\subsubsection{Internal Relative Humidity}

The behaviour of the relative humidity is closely linked to the type of climate control used, air conditioning. This system uses large quantities of air to heat or cool the rooms. Since the system is not equipped with a humidification system, it will generally always dry out the air it brings in from the outside, whether it cools or heats it. During the summer, this is not a major problem as the indoor humidity is kept within reasonable limits. However, during the winter, the humidity drops to excessively low values, $20 \%$ even. This places the building in high discomfort areas. It should be taken into account that in buildings constructed with a metal structure, low humidity is more of a problem. In office buildings with many metal parts, structure, tables, photocopiers, electric systems, low levels of relative humidity $<50 \%$, can generate particularly in women a disease called "semi-circular lipoatrophy" (SL) [18].

\subsection{Thermal Comfort Assessment}

Based on the monitored data, finally the degree of thermal comfort of the users has been evaluated, which will allow a comparison between the users' perception obtained through the surveys and the monitored data. To visualize the comfort of using the empirical model of the European standard UNE-EN ISO 7730 and the one in force in Spain implemented in the Technical Building Code (CTE). Note that the limits of model UNE-EN ISO 7730 are obtained for Category II with a MET of 1.1 and a CLO 1 in winter and 0.5 in summer. This study assumes an air speed of $1 \mathrm{~m} / \mathrm{s}$ for all administrative spaces.

In addition, the study will consider two new comfort assessment criteria (see Table 1). The first is the Regulation of Thermal Installations in Buildings - RITE [19]. This regulation establishes the set values for designing thermal installations in buildings In Spain, the RITE, in its 2009 update, set the air temperature of offices between $23-25^{\circ} \mathrm{C}$ (summer) and between $21-23{ }^{\circ} \mathrm{C}$ (winter) and a relative humidity of 45-60\% (summer) and 40-50\% (winter). 
Finally, this study considers the ideal temperature criteria defined by the National Institute of Occupational Safety and Health - INSHT [20]. In order to achieve an office temperature with less than a $10 \%$ margin of dissatisfaction, INSHT recommends temperatures of $23-26^{\circ} \mathrm{C}$ (summer) and between $20-24{ }^{\circ} \mathrm{C}$ (winter). The relative humidity of the air should be between $30 \%$ and $70 \%$. However, the existence of static electricity in the office must be considered here. Normally, air conditioning dries out the environment and encourages this unpleasant phenomenon. In this case, the recommended humidity should not fall below $50 \%$.

TABLE 1. SUMmary OF THE COMFORT ASSESSMENT CRITERIA OF THE NATIONAL STANDARDS USED IN ADDITION TO UNE-EN ISO 7730

\begin{tabular}{lcc}
\hline Standard & Operative Temperature, ${ }^{\circ} \mathrm{C}$ & Relative Humidity, \% \\
\hline RITE - Winter & $21-23{ }^{\circ} \mathrm{C}$ & $40-50 \%$ \\
RITE - Summer & $23-25^{\circ} \mathrm{C}$ & $45-60 \%$ \\
INSHT - Winter & $20-24^{\circ} \mathrm{C}$ & $30-70 \%$ \\
INSHT - Summer & $23-26^{\circ} \mathrm{C}$ & $30-70 \%$ \\
\hline
\end{tabular}

Although during the original study the degree of comfort of all the previously defined areas has been evaluated, this section mainly focuses on showing the results of the evaluation of the thermal comfort of one of the rooms with the highest degree of discomfort according to the results of the user surveys. In this case, one office on the first floor and the ground floor office have been selected (F1.5 and F0.1, respectively).

This study considers only working hours (from Monday to Friday, between 7:00-20:00).

\subsubsection{Winter Behaviour}

The temperatures are hardly in the comfort range (see Fig. 6 and Fig. 7). The hours outside the comfort ranges correspond in some cases to non-working hours, but in others to the beginning of the working day, when the system is not able to respond effectively to the overheating of the office. There is a high variation between the minimum $\left(9.7^{\circ} \mathrm{C}\right.$ in $\mathrm{F} 1.5$ office and $13.2^{\circ} \mathrm{C}$ in F0.1 office) and maximum $\left(32.1{ }^{\circ} \mathrm{C}\right.$ in $\mathrm{F} 1.5$ office and $24.3^{\circ} \mathrm{C}$ in $\mathrm{F} 0.1$ office) temperatures. The percentages of working hours within the comfort range of $21-23{ }^{\circ} \mathrm{C}$ are $16.2 \%$ (F1.5 office) and $62.5 \%$ (F0.1 office) throughout the winter.

The humidity limits in winter exceed the inferior limit (46.5\% and $60.4 \%$ working hours below $40 \%$ RH in F1.5 and F0.1 office respectively), even more so if the authors consider the values of the current RITE standard which establishes a margin of 40-50\% RH and the values established by the INSHT which limits for this type of space (air conditioning, metal structure, static electricity production elements). This is accentuated in the months of March-April (83.1\% and $98.8 \%$ working hours below $40 \% \mathrm{RH}$ in F1.5 and F0.1 offices respectively). In the comfort ranges marked by the RITE, the authors find a reduced number of hours throughout the winter within the comfort range (79 hours, $3.2 \%$ of all working hours in F1.5 office; and 787 hours, $31.4 \%$ of all working hours in F10.1 office). The INSHT range is more often met (714 hours, $14.3 \%$ ), but still far below the desirable comfort level. 


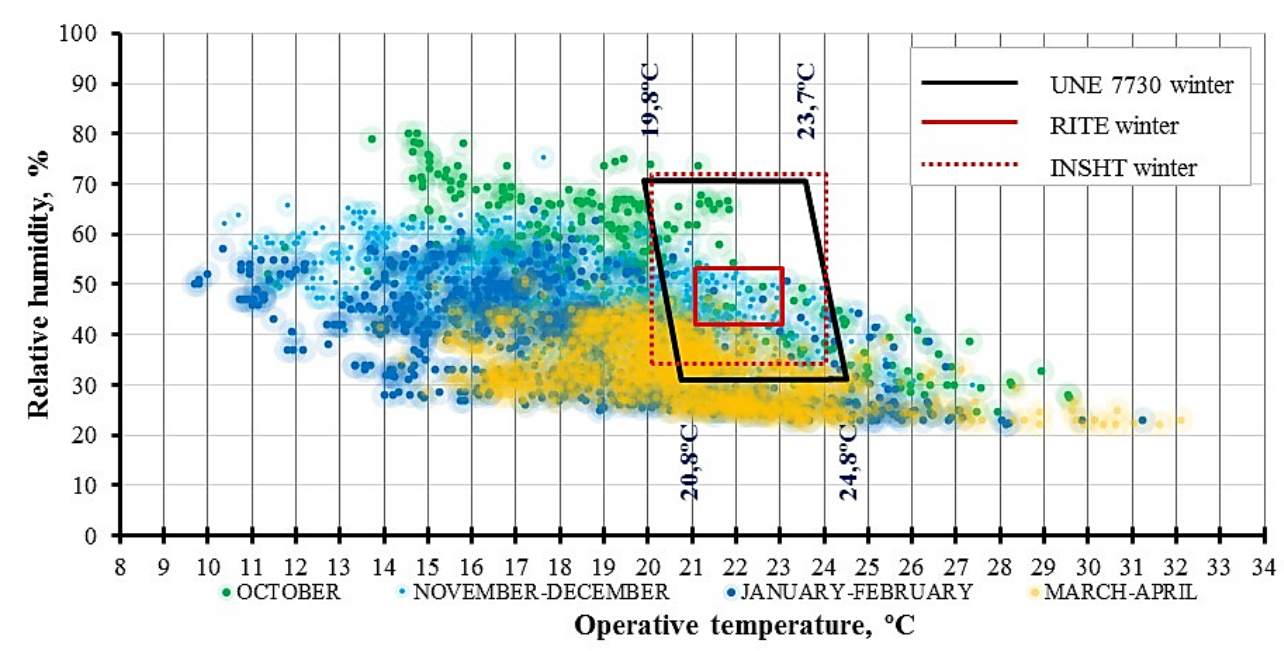

Fig. 6. Analysis of thermal comfort of room F1.5 during the winter.

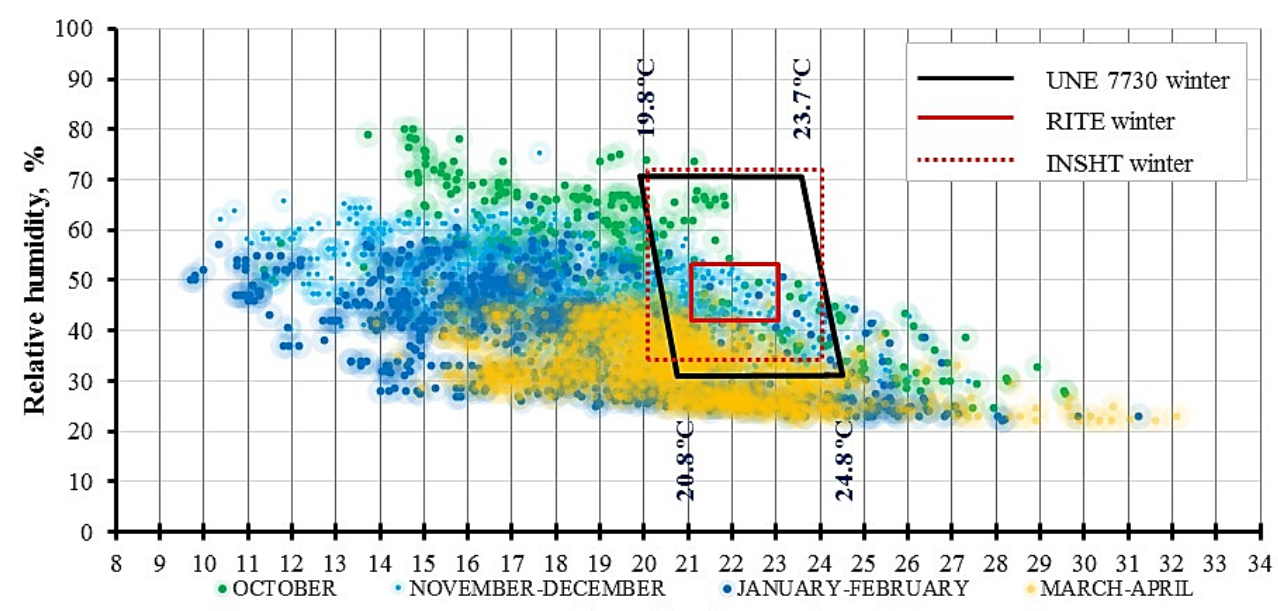

Operative temperature, ${ }^{\circ} \mathrm{C}$

Fig. 7. Analysis of thermal comfort of room F0.1 during the winter.

\subsubsection{Summer Behaviour}

The behaviour in summer is somewhat better than in winter (see Fig. 8 and Fig 9). In this case, the comfortable outside environment allows windows to be opened and to achieve better percentages of temperature and relative humidity within the comfort ranges of the various regulations. Note that in this case, monitoring fails for a wide range of hours (10-05-2018/24-072018), so the data are distorted in the months of May, June and July. A temperature of $24^{\circ} \mathrm{C}$ and $50 \%$ humidity has been set (red dot on the graph) so as not to distort the data. If the study considers the months of August and September, it can reach better conclusions about what happens in the 
comfort of the offices during the hottest months of the year. It is also necessary to indicate that the occupation during the month of August is lower than other months.

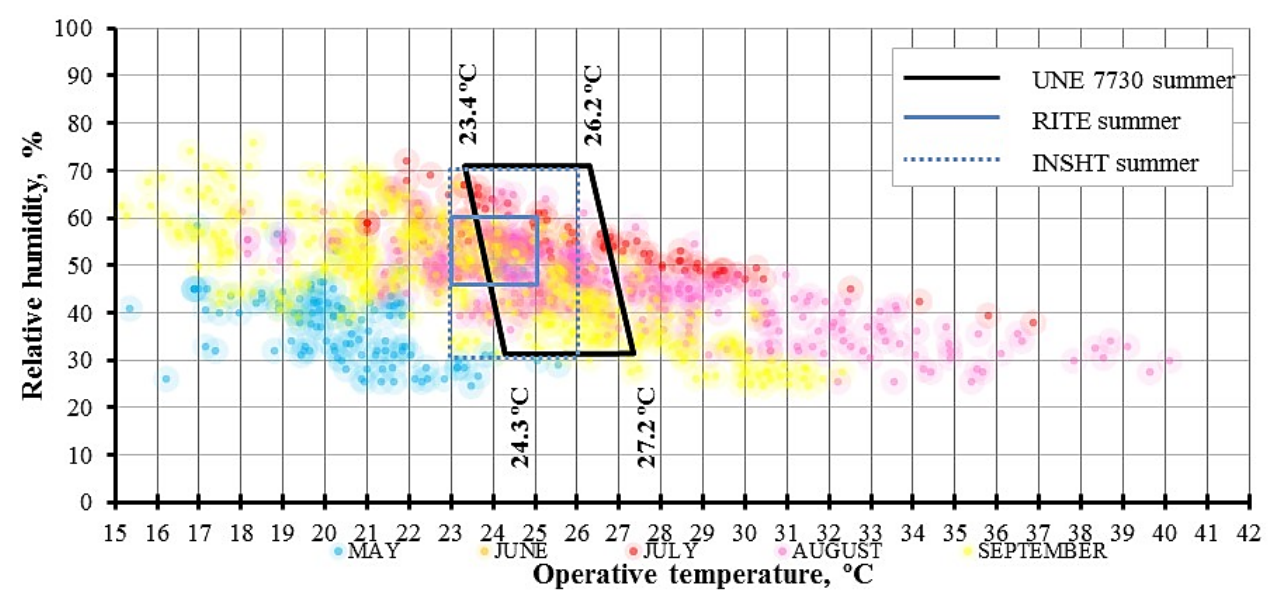

Fig. 8. Analysis of thermal comfort of room F1.5 during the summer.

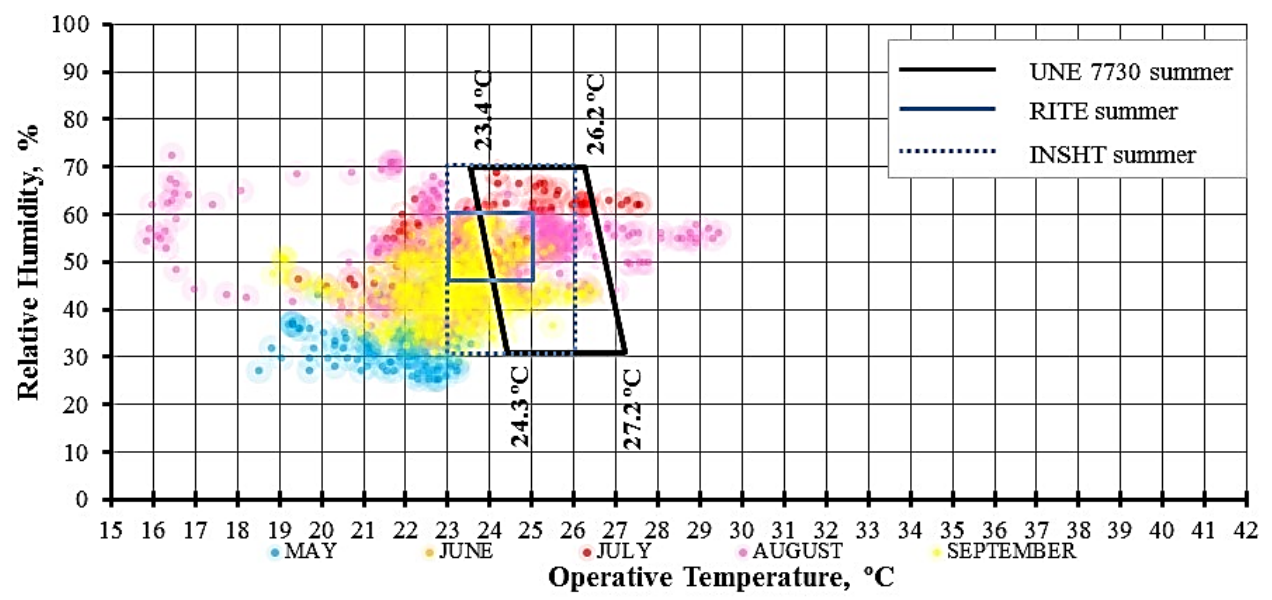

Fig. 9. Analysis of thermal comfort of room F0.1 during the winter.

The data of the F1.5 office reflect that the maximum temperature is reached in the month of August with $40.1{ }^{\circ} \mathrm{C}$. The peak values of May and July being $29.9{ }^{\circ} \mathrm{C}$ and $36.9{ }^{\circ} \mathrm{C}$, respectively. Even in September, in full industrial activity, value of $32.3{ }^{\circ} \mathrm{C}$ is reached. These values appear when the refrigeration equipment is disconnected. The system, however, struggles to reach adequate comfort temperatures. The relative humidity is closer to the comfort values, with the majority being in the $30-70 \%$ range. The data of the $\mathrm{F} 0.1$ office reflect that the maximum temperature is reached in the month of August with $29.5^{\circ} \mathrm{C}$, a much lower value than the data monitored in the offices on the first floor. 
According to the comfort ranges marked by the RITE and INSHT, the authors find that the behaviour of F1.5 and F0.1 offices is different (see Table 2). In the office F1.5, the number of working hours throughout the summer within the comfort range is reduced (139 hours, $14.6 \%$ of all working hours according to RITE; and 288 hours, $30.3 \%$ of all working hours according to RITE). However, the data of the F0.1 shows 1120 (61.1\%) and 1342 (73.2\%) working hours within the comfort range of RITE and INSHT respectively.

TABLE 2. SUMMARY OF THE NUMBER OF HOURS IN RELATION TO DIFFERENT INDOOR AIR TEMPERATURE AND RELATIVE HUMIDITY LIMITS IN WINTER AND SUMMER

\begin{tabular}{|c|c|c|c|c|c|}
\hline \multicolumn{3}{|c|}{ Winter period } & \multicolumn{3}{|c|}{ Summer period } \\
\hline & F1.5 office & F0.1 office & & F1.5 office & F0.1 office \\
\hline Total working hours & 2506 & 2506 & Total working hours & 1834 & 1834 \\
\hline Hours $<21{ }^{\circ} \mathrm{C}$ & 1777 & 855 & Hours $<23^{\circ} \mathrm{C}$ & 1227 & 422 \\
\hline Hours $21-23^{\circ} \mathrm{C}$ (comfort RITE) & 407 & 34 & Hours $23-25^{\circ} \mathrm{C}$ (comfort RITE) & 205 & 1253 \\
\hline Hours $>23^{\circ} \mathrm{C}$ & 322 & 85 & Hours $>25^{\circ} \mathrm{C}$ & 402 & 159 \\
\hline Hours $>28^{\circ} \mathrm{C}$ & 26 & 0 & Hours $>28^{\circ} \mathrm{C}$ & 187 & 14 \\
\hline $\begin{array}{l}\text { Hours HR } 40-50 \% \\
\text { (comfort RITE) }\end{array}$ & 705 & 910 & $\begin{array}{l}\text { Hours HR 45-60 \% } \\
\text { (comfort RITE) }\end{array}$ & 441 & 1351 \\
\hline Hours $\mathrm{HR}<40 \%$ & 1243 & 1513 & Hours $\mathrm{HR}<45 \%$ & 1296 & 395 \\
\hline Hours HR $>50 \%$ & 558 & 83 & Hours HR > $60 \%$ & 97 & 85 \\
\hline Comfort UNE & 245 & 1123 & Comfort UNE & 195 & 1228 \\
\hline Comfort RITE & 79 & 787 & Comfort RITE & 139 & 1120 \\
\hline Comfort INSHT & 546 & 1453 & Comfort INSHT & 285 & 1342 \\
\hline
\end{tabular}

In order to close this section of comfort evaluation, the conclusions obtained after analysing the monitored data from other relevant rooms of this building are summarized: the large office on the first floor (F1.1). As it is located in a north-western area and has more contact with unheated spaces, it behaves in a more extreme manner. The minimum temperature reached in winter is $6.3{ }^{\circ} \mathrm{C}$, with a minimum humidity of $23 \%$. Winter comfort according to RITE is only reached in $0.7 \%$ of the time ( 34 hours), $15.3 \%$ according to INSHT. The environment is very dry as large amounts of air are needed to climate the space. $37.7 \%$ of the working hours are below $40 \% \mathrm{RH}$. The maximum temperature reached is $26.8^{\circ} \mathrm{C}$. In August a peak temperature of $34.0{ }^{\circ} \mathrm{C}$ is reached. Comfort in September according to RITE is only reached in $11.2 \%$ of the time ( 81 hours), $32.5 \%$ according to INSHT. During this period, adequate HR rates were maintained at 30-70\% (47.7\% of September hours).

\section{CONCLUSIONS}

This work has made it possible, on the one hand, to confirm that the deficient enclosure of the office space generates large heat losses in winter that lead to high consumption by the airconditioning systems without obtaining adequate comfort in return. Likewise, the high glazed surface area with solar protection systems on the inside causes strong contrasts in the interior temperature, especially in the offices located on the upper floor which the air conditioning equipment is not capable of managing adequately. This generates a situation of generalised 
discomfort in the workers due to a bad temperature and relative humidity outside the ranges recommended by the regulations in spite of the high consumption of the HVAC equipment. In a second phase of this study, a series of measures to improve the enclosure are proposed, aimed at increasing the periods within the comfort ranges and reducing the energy consumption of the airconditioning systems.

\section{ACKNOWLEDGEMENT}

The authors appreciate the support of PANELFISA and of the TOLOSALDEA LHII. Furthermore, the authors thank the Department of Architecture and the Vicerrectorate for Research of the University of the Basque County UPV/EHU for the financial support given for this research.

\section{REFERENCES}

[1] Wagner A., et al. Thermal comfort and workplace occupant satisfaction-Results of field studies in German low energy office buildings. Energy and Buildings 2007:39(7):758-769. https://doi.org/10.1016/j.enbuild.2007.02.013

[2] Alajmi A. F., Baddar F. A., Bourisli R. I. Thermal comfort assessment of an office building served by under-floor air distribution (UFAD) system - A case study. Building and Environment 2015:85:153-159. https://doi.org/10.1016/j.buildenv.2014.11.027

[3] De Vecchi, R., Candido C., de Dear R., Lamberts R. Thermal comfort in office buildings: Findings from a field study in mixed-mode and fully-air conditioning environments under humid subtropical conditions. Building and Environment 2017:123:672-683. https://doi.org/10.1016/j.buildenv.2017.07.029

[4] Rupp R. F., Ghisi, E. Predicting thermal comfort in office buildings in a Brazilian temperate and humid climate. Energy and Buildings 2017:144:152-166. https://doi.org/10.1016/j.enbuild.2017.03.039

[5] Gladyszewska-Fiedoruk K. Survey Research of Selected Issues the Sick Building Syndrome (SBS) in an Office Building, Environmental and Climate Technologies 2019:23(2):1-8. https://doi.org/10.2478/rtuect-2019-0050

[6] Katafygiotou M. C., Serghides D. K. Thermal comfort of a typical secondary school building in Cyprus. Sustainable Cities and Society 2014:13:303-312. https://doi.org/10.1016/j.scs.2014.03.004

[7] Jindal A. Thermal comfort study in naturally ventilated school classrooms in composite climate of India. Building and Environment 2018:142:34-46. https://doi.org/10.1016/j.buildenv.2018.05.051

[8] Yang B., Olofsson T., Wang F., Lu W. Thermal comfort in primary school classrooms: A case study under subarctic climate area of Sweden. Building and Environment 2018:135:237-245. https://doi.org/10.1016/j.buildenv.2018.03.019

[9] Becker R., Paciuk M. Thermal comfort in residential buildings - Failure to predict by Standard model. Building and Environment 2009:44(5):948-960. https://doi.org/10.1016/j.buildenv.2008.06.011

[10] Peeters L., Dear R. de Hensen J., D'haeseleer W. Thermal comfort in residential buildings: Comfort values and scales for building energy simulation. Applied Energy 2009:86(5):772-780. https://doi.org/10.1016/j.apenergy.2008.07.011

[11] Yu W., Li B., et al. A study of thermal comfort in residential buildings on the Tibetan Plateau, China. Building and Environment 2017:119:71-86. https://doi.org/10.1016/j.buildenv.2017.04.009

[12] Eustat. Euskal Estatistika Erakundea. Panorama de la Industria Vasca 2018. (Basque Statistical Institute. Panorama of the BAsque Industry 2018.) [Online]. [Accessed 08.04.2020]. Available: https://es.eustat.eus/elementos/ele0015400/Panorama_de_la_Industria_Vasca/inf0015432_c.pdf_(in Basque)

[13] Albatayneh A., Alterman D., Page A., Moghtaderi B. The Significance of Building Design for the Climate. Environmental and Climate Technologies 2018:22:1:165-178. https://doi.org/10.2478/rtuect-2018-0011

[14] Government of Spain. Ministry of Fomento, "Spanish Technical Building Code, basic document DB-HE 'Energy saving,' 2013 [Online]. [Accessed 08.04.2020]. Available: https://www.codigotecnico.org/

[15] ISO 7730. Ergonomics of the thermal environment Analytical determination and interpretation of thermal comfort using calculation of the PMV and PPD indices and local thermal comfort criteria. Management, 2005.

[16] Jimenez-Bescos C., Oregi X. Implementing User Behaviour on Dynamic Building Simulations for Energy Consumption. Env. \& Climate Technologies 2019:23(3):308-318. https://doi.org/10.2478/rtuect-2019-0097

[17] MyOpenHab Homepage [Online]. [Accessed 16.12.2019]. Available: https://www.myopenhab.org/

[18] Linares-García Valdecasas R. et al. Semicircular lipoatrophy: An electrostatic hypothesis. Dermatology 2015:230(3):222-227. https://doi.org/10.1159/000370045

[19] Ministry of Industry, Energy and Tourism. Reglamento de Instalaciones Térmicas En Los Edificios. (Regulations oof thermal Installations in Buildings.) Boletin Oficial Del Estado, 2013. (in Basque)

[20] INSHT (National Institute for Safety and Health at Work) [Online]. [Accessed 07.01.2020]. Available: https://www.insst.es/ 